\title{
A PROPÓSITO DE UMA VOCAÇÃO PARA O CHISTE DA CULTURA BRASILEIRA
}

Antônio M. R. Teixeira

UFMG

\begin{abstract}
RES U MO
O autor se propõe a interrogar quanto a uma possível vocação da cultura brasileira para o chiste, considerando o modo pelo qual o sujeito, ali inserido, responderia a um apelo que ela própria lhe dirige por um gesto que coloca em suspenso o funcionamento de suas regras internas.
\end{abstract}

\section{PALAVRAS - CHAVE}

Chiste, Cultura brasileira, Vocação, Sobrinho de Rameau, Macunaíma.

\section{Todos nós herdamos, do sangue lusitano, uma boa dosagem de lirismo, ... além da sifilis, é claro! \\ (Chico Buarque EF Rui Guerra, "Fado tropical")}

\begin{abstract}
No momento em que, por ocasião de um debate literário-filosófico, fui convidado pela primeira vez a falar - desde esse lugar indefinido em que habita o psicanalista - acerca de uma suposta vocação da cultura brasileira para o chiste, o estado de errância em que me encontrava, acrescido de um quase completa ignorância com relação ao assunto, conduziume como que por urgência a procurar, em cada palavra do título proposto ao tema, a sinalização de algum caminho a seguir. Ocorreu-me então, por felicidade, desvelar uma pista a partir do uso mesmo que se faz do termo vocação para tratar de tal conjectura.

Se decidi prosseguir nessa via, foi por considerar, de saída, que se a noção de vocação se confundisse com as idéias que freqüentemente lhe aplicamos, tais como as de talento inato, de dom natural ou de inclinação, a questão perderia sua pertinência: a cultura não se deixa pensar em termos de natureza, o que priva de sentido toda questão acerca de uma tendência natural relativa a qualquer cultura. Justifica-se, portanto, explorar minimamente a especificidade semântica do termo vocação, a partir do momento em que ele se separa de toda referência a um dom natural ou inato da cultura brasileira para produzir o chiste. Vocação é, aliás, um conceito que mereceu uma grande atenção em certos estudos sobre os fenômenos da cultura, como bem sabem os leitores familiarizados com Max Weber, o qual lhe consagrou um capítulo inteiro em seu livro sobre a ética protestante, assim como uma longa pesquisa historiográfica inserida numa nota de pé de página (WEBER, 1989, p. 81-104). Interessa a Max Weber definir, ao tratar do uso da noção de Beruf, em Lutero, o apelo religioso capaz de
\end{abstract}


explicar o elemento de irracionalidade subjacente ao espírito do capitalismo, cuja devoção metódica ao trabalho e à acumulação de capital de longe ultrapassa as finalidades do bemestar do indivíduo. Vale a pena extrair dali a noção de apelo ou de chamado para precisar o significado por ele explorado da noção de Beruf (em inglês: calling), no sentido em que ela nos autoriza a pensar a idéia de vocação nos termos de uma resposta do sujeito a um apelo vindo do Outro. Trata-se, no estudo de M. Weber, de um apelo sobre o qual se funda o fator de crença subjacente à ética do capitalismo, o qual nos permite conceber a devoção ao trabalho na forma de uma tarefa delegada aos homens por Deus.

Descartada, portanto, a idéia de interrogar quanto a uma tendência natural da cultura brasileira para o chiste, poderíamos então reformular a pergunta e interrogar se existe, na cultura brasileira, um apelo vindo do Outro que nos convoca a produzir o chiste. Tal reformulação nos parece promissora, posto que uma das condições essenciais para a produção do chiste consiste justamente na referência ao Outro enquanto terceiro termo, para além do trabalho do chiste (Witzarbeit), ou da elaboração técnica do significante. O auditório é uma das condições essenciais para a realização do chiste, como se verifica no fato de que aquele que o produz rir somente após ver surtir o efeito cômico sobre as outras pessoas ${ }^{1}$.

O chiste se dá assim como um processo essencialmente social. Dali, além disso, se explica, segundo B. Cassin, sua diferença para com o efeito cômico e sua afinidade para com o asteion, cujos traços de fineza e elegância fazem a urbanitas das capitais ${ }^{2}$. O chiste se demarca do traço puramente cômico na medida em que requer a sanção do Outro, sem a qual ele não passaria de um acidente verbal. Cumpre, contudo, salientar, na esteira de Lacan, que seu endereço, no campo do Outro, não se encontra especificado por nenhum acordo prévio. $\mathrm{O}$ Outro do chiste se configura como uma paróquia, para retomarmos a expressão de Bergson, no momento em que se constitui ao modo de uma forma vazia, ou seja, um campo de inibições a delimitar o modo de gozo que convém, assim como o que deve e pode ser dito (LACAN, 1998, p. 118).

Eis porque composições significantes tais como "Fornicar?" somente têm efeito de Witz na paróquia psicanalítica ${ }^{3}$. Quem já tentou, sem êxito, produzir um chiste em língua estrangeira, como o autor dessas mal traçadas linhas, sabe o quão importante é a influência da paróquia para o efeito espirituoso da palavra escolhida. Mas seja como for, não deixa de ser curioso observar o quanto o chiste depende, para ocorrer, de uma infração significante produzida no campo do Outro, seja através da criação de neologismos como familionário, para retomarmos o exemplo clássico de Freud, seja mediante uma redistribuição semântica de determinados fonemas sem utilização prevista pelas regras da linguagem, como no caso da célebre pergunta de Dom Pedro II - Que mal há? - em referência ao barão de Mauá. No

${ }^{1}$ Cf. sobretudo o capítulo V do livro que Freud consagra ao chiste enquanto fenômeno social (FREUD, 1999).

${ }^{2}$ A se notar que o termo asteion, que Barbara Cassin aproxima da noção de agudeza, tal como a concebe Balthasar Gracián (GRACIÁN, B. Agudeza y arte del ingenio, Madrid: Ed. Evaristo Correa, 1988), faz referência ao princípio de economia que confere ao Witz o brilho particular, através do qual seu autor se faz notar na sociedade (CASSIN, 1995, p. 388).

${ }^{3}$ O chiste aqui opera sobre o nome "Ornicar?", que dá o título a uma das principais revistas de psicanálise de orientação lacaniana. 
que diz então respeito ao exame de uma suposta vocação da cultura brasileira para o chiste, a pergunta que finalmente se coloca seria, pois, a de saber se existe, da parte do Outro, o apelo por um gesto que justamente coloca em causa a consistência de suas regras.

Para irmos diretamente ao ponto, notemos, junto a Freud, que o ganho de prazer (Lustgewinn) suscitado pelo verdadeiro Witz - o Witz tendencioso, em suas palavras -, resulta do acesso por ele aberto a uma satisfação pulsional normalmente impedida pelo recalque. Ao romper, mediante jogos de palavra, os limites convencionais colocados pelas regras do uso da linguagem, o chiste nos permite igualmente franquear os limites do pudor que nos retém pelo recalque. Seu efeito de riso se deve assim à satisfação pulsional que nos leva sutilmente a admitir, ao nos revelar, pela via do nonsense, o aspecto derrisório do limite a nos impedir de experimentar essa satisfação.

Se quisermos então falar de uma vocação subjetiva para o chiste, dentro de uma determinada cultura, caberia supor que o sujeito que responde a esse apelo executa uma função social em certo ponto análoga àquela que Foucault atribui ao "Neveu de Rameau", em sua História da Loucura. O sobrinho de Rameau, para quem o desconhece, é o protagonista de um ensaio sobre a moral composto em forma de diálogo pelo filósofo Diderot, que o descreve como um mélange de fanfarronice, falta de caráter e cinismo. Seu personagem vem representar, ainda no século XVIII, o tipo social vil e grotesco que é ao mesmo tempo desprezado e querido. As pessoas da sociedade o repelem ao mesmo tempo em que o conservam, na medida em que ele lhes oferece a única possibilidade de fruir razoavelmente, pela via do chiste e da pantomima, da satisfação indevida do disparate, do comportamento excessivo, do desatino. Ele é o louco do qual as pessoas razoáveis precisam para não morrer de enfado ${ }^{4}$. Sua insanidade se torna assim, no dizer de Foucault, um obscuro objeto de desejo que a razão quer possuir malgrado ela mesma. Se ela traduz a alienação do espírito de nobreza na consciência vil de que falava Hegel, é que a razão encontra, nesta relação com a loucura, a única saída para escapar da aridez de seu formalismo. A razão se vê obrigada a estabelecer com a insanidade, como exprime Foucault, uma relação de obscura dependência, para não se ver confinada ao tédio de sua existência monótona e vazia (FOUCAULT, 1972, p. 343-344).

De mais a mais, não é excessivo salientar que, nessa representação, o desatino seja o recurso do sujeito indigente, premido pela necessidade, que nunca sabe ao certo quando terá o que comer nem aonde vai poder dormir. O indivíduo excluído, que sofre da carestia, não caminha como qualquer outro, diz o sobrinho de Rameau: ele é aquele que "pula, rasteja, se contorce, se arrasta, passa a vida a assumir e a executar posições”. Assim, no rigor racional da necessidade inapelável, o homem necessitado se faz valer, paradoxalmente, como oferta do desnecessário, do inútil! Ele se serve do fascínio que o inessencial provoca para despertar, nas pessoas que se acreditam razoáveis, a avidez pelo excesso que seu comportamento denota: uma espécie de gozo suplementar normalmente impedido pelo bom uso da razão.

Voltando agora à pergunta inicial acerca da vocação de nossa cultura para o chiste, há algo que, ao que parece, aproxima o personagem vil de Diderot de uma figura que se tornou, em determinado momento, emblemática da cultura brasileira: refiro-me, naturalmente, ao herói sem nenhum caráter, imortalizado por Mário de Andrade no personagem de Macunaíma.

${ }^{4}$ «Imaginez l'univers sage et philosophe; convenez qu'il serait diablement triste.» (DIDEROT, 1951, p. 422). 
Tal como acontece com o sobrinho de Rameau, existe, em Macunaíma, algo que define o brasileiro como o sujeito indigente, sem provisão, obrigado a se arranjar com o que encontra diante de si. Constantemente incitado pelos estímulos do prazer e do medo, sua ética está em contraponto frontal com a lei moral kantiana. Glutão, indolente, lascivo e devasso, ele é o exemplo mais claro do indivíduo patológico, inteiramente orientado pelas inclinações sensíveis.

Cumpre, todavia, estender o epíteto "sem nenhum caráter" para além de sua conotação moral, se quisermos pensar naquilo em que esse personagem reflete a cultura do Brasil. "Herói sem nenhum caráter" quer igualmente dizer: herói de uma identidade impossível, herói proteiforme, de imagens desencontradas e incoerentes, que não admitem síntese alguma. Nessa perspectiva, propõe Alfredo Bosi, Macunaíma é a resposta que encontra Mário de Andrade em seu desejo de pensar o povo brasileiro, à procura de uma identidade que, de tão plural, beira a surpresa e a indeterminação (BOSI, 1996, p. 178). Temos assim Macunaíma, o plagiador; Macunaíma, o contrabandista; Macunaíma, a francesa; Macunaíma, o embusteiro; e, sobretudo, o herói da falácia e dos jogos de linguagem, herói do sofisma e da metamorfose que transforma São Paulo, a civilização do trabalho, num grande bicho preguiça... Não deixa de ser interessante pensar que a epopéia do herói sem nenhum caráter, em cuja imagem inconstante se reflete a miríade das situações do país, venha tecer, nos termos de Eneida Maria de Souza, uma das reflexões mais agudas sobre a identidade nacional (SOUZA, 1993, p. 347). No lugar em que toda identidade coletiva se fixa sobre um ponto de segregação, em sua necessidade constante de uma referência negativa, Macunaíma faz transitar o Brasil autóctone do indígena não integrado. Metáfora viva da metamorfose, ele apresenta (posto que não representa) o Brasil em sua síntese impossível.

Tamanha indeterminação termina por colocar a perder, em que pese o brilhante empenho de Sérgio Buarque de Holanda, toda possibilidade de se pensar a vocação do brasileiro (ou da cultura brasileira) mediante a representação weberiana de um ideal-tipo. Mas se quisermos, ainda assim, atermo-nos a uma pista para sondar que possível resposta o personagem de Macunaíma veicula, vale lembrar, com A. Bosi, que Mário de Andrade dedicara sua obra ao ensaísta Paulo Prado, o qual havia publicado, no mesmo ano (1928), um sombrio e instigante estudo intitulado Retrato do Brasil. Neste sublime Ensaio sobre a tristeza brasileira - cuja reedição se deve à louvável iniciativa de Carlos Augusto Calil -, Paulo Prado nos conduz a ver a causa de nossa histórica propensão à tristeza na tríade "luxúria, cobiça, melancolia" (PRADO, 1998, p. 142 e sq.). Em contraponto com a vocação puritana que condicionou a prosperidade da América do Norte, haveria, segundo este autor, como conseqüência da sensualidade exacerbada de nossa cultura, da paixão sem finalidade do desvario erótico, um enfraquecimento de espírito no limite incompatível com o projeto civilizatório.

"Post coitum animal triste, nisi gallus qui cantat", sentenciava Paulo Prado, citando o célebre aforismo esculápio. Se for possível conjecturar acerca de uma resposta de Mário de Andrade à tese de Paulo Prado, diríamos então que é a triste visão dessa psicastenia brasileira que Macunaíma inverte, ao estampar, com alegria implacável, a sensualidade brasileira não mais como uma indolência mórbida, porém ao modo de uma preguiça afirmativa.

Assim, o herói, que de primeiro passou mais de seis anos não falando, se o incitavam a falar exclamava: "Ai! que preguiça!...". Vê-se de imediato, no primeiro parágrafo de Macunaíma, que a exclamação do ócio constitui seu personagem, definindo seu modo mesmo 
de entrada no registro da linguagem. Em vez de deplorar, como fazia Paulo Prado, a recusa romântica da realidade, cujo pessimismo tanto contaminara nossa cultura, Mário de Andrade prefere troçar desse egocentrismo sentimental, dispondo a subjetividade do herói como uma recusa alegre, isenta do recurso parnasiano ao beletrismo. Figura em que se destaca a tão proverbial indolência indígena, em cujas mãos, como diria mais tarde Gilberto Freire, a enxada jamais se fixaria (FREIRE, 2003, p. 163), Macunaíma converte por fim a dignidade em direito à preguiça. Sem compromisso com a disciplina do trabalho à qual a civilização obriga, esse personagem anuncia, na literatura, o que Pierre Clastres, em A Sociedade contra o Estado, iria constatar na etnografia. Por isso tanto nos encanta o aspecto lúdico de seu comportamento sensualista; para alcançar o que deseja, as regras e as convenções sociais são por ele tratadas como um mero jogo de pantomimas.

Há, portanto, uma diferença profunda que separa o personagem de Mário de Andrade do personagem de Diderot, no sentido em que para o primeiro, ao contrário do que acontece com o sobrinho de Rameau, não se trata de opor a realidade à farsa que a sociedade representa. A realidade é ela mesma tratada como uma farsa, uma pantomima, podendo ser indefinidamente desfeita e recomposta conforme o fim que se almeja. A quem quiser qualificar seu comportamento nômade como uma fuga da realidade, diríamos que talvez seja disso mesmo que se trata. Trata-se sim, de uma fuga, mas de uma fuga no sentido em que Deleuze a percebe, quando ele diz que ela não é um gesto passivo (DELEUZE, 1998, p. 49). Fugir implica se armar, produzir uma evasão, um estado impessoal de potência capaz de criar uma ruptura. É preciso, como diz Deleuze, fazer fugir, fazer vazar o sistema normativo da realidade como quem fura um cano, fazer jorrar um devir insuspeitado sem o apelo romântico da transcendência, no plano imanente da geografia mundana. É nessa perspectiva que a trajetória de Macunaíma constitui uma linha de fuga, ao modo de um devir geográfico errante que seu percurso pelo Brasil metaforiza.

Há, por conseguinte, uma vocação essencialmente política a ser destacada nessa recusa cômica da realidade, nessa parvoíce aparentemente inocente de Macunaíma. Pois ainda que o herói, assim representado, pareça por vezes um tolo ou um retardado, é da boca do sujeito parvo que saem, diz Lacan (LACAN, 1986, p. 215), as verdades que são não somente toleradas, mas colocadas em função através de sua bufonaria. $O$ que define o valor do intelectual de esquerda, aos olhos de Lacan, é justamente essa foolery fundamental que Mário de Andrade aciona através de Macunaíma. Ele desloca a verdade do discurso normativo, fazendo-a exercer sua função subversiva pela via supostamente inocente do homem néscio, em sua tolice. Em contraponto a esse acionamento néscio da verdade pelo desejo, a canalhice filosófica, que Lacan atribui ao intelectual de direita, consiste justamente na pretensão de querer dizer, pela via da metalinguagem, a verdade sobre o verdadeiro. Quando buscamos nos assegurar de uma norma da verdade, tratando-a como propriedade de uma fórmula fixa, da verdade já não mais resta grande coisa. É por querer salvar a verdade na estabilidade de um enunciado, elidindo o risco e o jogo da enunciação, que o discurso filosófico termina por lhe fechar a porta, afirmava Lacan em sua resposta aos estudantes de filosofia, no ano de 1966 (LACAN, 2001, p. 204).

Percebe-se então que Macunaíma, embora se sirva habilmente da retórica e dos jogos de linguagem, não disserta, como o sobrinho de Rameau, sobre o uso que dela faz. Ele não tece metalinguagem sobre sua linguagem. A única reflexão que ele faz sobre a ordem do 
mundo e das coisas se resume a declarar a contrariedade do seu desejo, exprimindo sua preguiça quando uma situação qualquer o demove de suas inclinações sensíveis. Em nenhum momento ele medita acerca da fórmula que lhe dê garantia de sua subsistência, pondo constantemente a perder os bens mundanos que havia obtido. Tudo o que fora a sua existência não fora senão, como diz o poeta, "um se deixar viver". Herói errante do encontro e do acaso, ele não poderia se furtar ao que o destino cômico lhe reservava em seu desfecho trágico. Sem ânimo para a renúncia e o trabalho que atrela o sentido da vida à realidade, Macunaíma prefere deixar de aqui ser.

E se vai, para brilhar no céu, o brilho belo e inútil de uma estrela...

\title{
A
}

\section{Rés U MÉ}

Lauteur se propose à interroger sur la possibilité d'une vocation de la culture brésilienne pour le mot d'esprit, tout en considérant la façon dont le sujet y inséré répond à un appel que cette culture elle-même lui adresse par un geste qui met en suspens le fonctionnement de ses règles à elle.

\author{
MOTS-CLÉS \\ Mot d'esprit, Culture brésilienne, Vocation, Neveu de \\ Rameau, Macunaíma.
}

\section{REFERÊNCIAS BIBLIOGRÁFICAS}

BOSI, Alfredo. Situação de Macunaíma. In: ANDRADE, Mário. Macunaíma, o herói sem nenhum caráter. Paris: Scipione Cultural (Edição crítica), 1996.

CASSIN, Barbara. L'effet sophistique. Paris: Gallimard, 1995.

DELEUZE, Gilles, PARNET, Claire. Diálogos. Trad. Eloísa Araújo Ribeiro. São Paulo: Escuta, 1998.

DIDEROT, Denis. Le neveu de Rameau. In: Diderot: CEuvres. Paris: Gallimard (Pléiade), 1951.

FREIRE, Gilberto. Casa grande e senzala. São Paulo: Global Editora, 2003.

FREUD, Sigmund. [1905] Der Witz und seine Beziehung zum Unbewussten. In: Gesammelte Werke. Frankfurt: Fischer Verlag, 1999.

LACAN, Jacques. Le séminaire - livre V: Les formations de l'inconscient. Paris: Seuil, 1998.

LACAN, Jacques. Le séminaire - livre VII: L'Éthique de la psychanalyse. Paris: Seuil, 1986.

LACAN, Jacques. Réponse aux étudiants de philosophie. In: Autres écrits. Paris: Seuil, 2001.

PRADO, Paulo. Retrato do Brasil: ensaio sobre a tristeza brasileira. São Paulo: Companhia das Letras, 1998.

SOUZA, Eneida Maria de. A pedra mágica do discurso. In: ANDRADE, Mário. Macunaíma, o herói sem nenhum caráter. Paris: Scipione Cultural (Edição crítica), 1996.

WEBER, Max. L'Éthique protestante et l'esprit du capitalisme. Trad. J. Chavy. Paris: Agora, 1989. 